\title{
A Socio-ecological Imperative for Broadening Participation in Coastal and Estuarine Research and Management
}

\author{
L.A. Harris ${ }^{1}$ (D) - T. Grayson ${ }^{2}$ • H.A. Neckles ${ }^{3}$ - C.T. Emrich ${ }^{4} \cdot$ K.A. Lewis ${ }^{5} \cdot$ K.W. Grimes ${ }^{6} \cdot$ S. Williamson ${ }^{7} \cdot$ C. Garza $^{8}$.

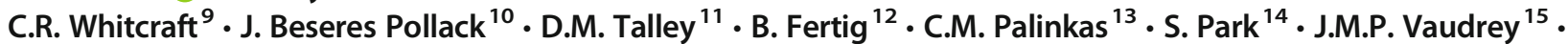 \\ A.M. Fitzgerald ${ }^{16} \cdot$ J. Quispe ${ }^{17}$
}

Received: 10 February 2021 / Revised: 23 April 2021 / Accepted: 27 April 2021 / Published online: 18 May 2021

(C) The Author(s) 2021

\begin{abstract}
For most of the scientific disciplines associated with coastal and estuarine research, workforce representation does not match the demographics of communities we serve, especially for Black, Hispanic or Latino, and Indigenous peoples. This essay provides an overview of this inequity and identifies how a scientific society can catalyze representational, structural, and interactional diversity to achieve greater inclusion. Needed changes go beyond representational diversity and require an intentional commitment to build capacity through inclusivity and community engagement by supporting anti-racist policies and actions. We want to realize a sense of belonging on the part of scientists in society at large and enable research pursuits through a lens of social justice in service of coastal communities. Minimally, this framework offers an avenue for increased recruitment of individuals from more diverse racial and ethnic identities. More broadly, the mechanisms described here aim to create a culture in scientific societies in which social justice, driven by anti-racist actions, produces systemic change in how members of scientific societies approach, discuss, and address issues of inequity. We have written this essay for members of the coastal and marine science community who are interested in change. We aim to call in new voices, allies, and champions to this work.
\end{abstract}

Keywords Justice $\cdot$ Equity $\cdot$ Diversity $\cdot$ Inclusion $\cdot$ Racism $\cdot$ Coastal communities $\cdot$ Professional societies

\section{Introduction}

Despite widespread recognition that increasing the participation of Black, Hispanic and Latino, and Indigenous peoples in science, technology, engineering, and mathematics (STEM) is essential to sustaining our capacity for innovation and discovery, STEM degree programs and occupations in the United States (National Research Council 2011; National Science Foundation 2019) and globally (e.g., Delaine et al. 2016) continue to lack demographic diversity. This fact is also true in the coastal, estuarine, and ocean sciences, where a gap persists between the number of marine-discipline graduate degrees granted and degree attainment by racial and ethnic populations

Communicated by Kenneth L. Heck

L.A. Harris

harris@umces.edu

Extended author information available on the last page of the article that remain underrepresented in these fields (Garza 2015; Johnson et al. 2016). According to data from the Integrated Post-Secondary Education Data System (IPEDS), Black or African American degree completion (combined undergraduate and graduate) in marine science at United States (USA) institutions is low and flat-lined, generally at $1 \%$ (or less) of the total number of marine science degrees granted between 2010 and 2019 (U.S. Department of Education 2020). For Hispanic students, graduation rates are only slightly higher with marine science degree completions steadily increasing over the same period from 2 to $13 \%$ of all awarded marine science degrees. Degree completion for both groups (Black and Hispanic) is substantially lower than their respective representation in the US population (13.4\% and $18.5 \%$, respectively; US Census 2020). Bernard and Cooperdock (2018) showed that over the last 40 years, the number of Ph.D.'s in atmospheric, earth, and ocean sciences awarded to students identifying as American Indian or Alaska Native, Black or African American, and Hispanic or Latino has remained exceedingly low despite extensive educational efforts to increase diversity among STEM students, particularly at the graduate level. Between 1973 and 
2016, fewer than $8 \%$ of 5138 ocean science Ph.D.'s were awarded to non-white or non-Asian graduates despite a significant increase in their proportion of the overall US population during those 40 years (Bernard and Cooperdock 2018). This discrepancy between recruitment efforts and representation points to a more systemic issue of bias and racism in the geosciences.

While these trends are reflective of the USA, international climate change policies informed by scientists have highlighted a global "North-South" divide in research that leads to similar inequities in representation. Blicharska et al. (2017) report that researchers from countries in the "North," which are classified as high-income economies, dominate the climate conversation at the expense of researchers representing countries from the "South," which the authors define as upper middle-income, lower middle-income, or low-income economies (largely countries in Asia, Africa, and Latin America). Efforts to implement inclusive structures at the Intergovernmental Panel on Climate Change (IPCC) have revealed continued gaps between institutional access by governments worldwide and actual participation (Yamineva 2017), similar to the patterns of attempted recruitment and lack of progress reported by Bernard and Cooperdock (2018). Despite equal procedural rights across all countries, geographical representation in IPCC participation reflects deep differences in the economic and social capacities of countries to engage. This North-South divide leads to imbalances in racial representation in the global science community. While the historic legacies contributing to these patterns on a global scale may differ, the resulting impact on diversity of the scientific community is similar to the USA. This same divide is seen in publication rates, which are higher for studies on ecosystems in temperate and cold latitudes, reducing our knowledge of sub-tropical and tropical ecosystems (Karlsson et al. 2007).

Without a marked increase in the racial and ethnic diversity of students obtaining geoscience degrees, all science fields including coastal sciences risk losing the capacity to do the best science and to design the best policy (Page 2007). By championing equitable representation of underrepresented groups in geosciences, coastal communities will better innovate in the face of a changing climate and thus a changing coastal system. The disparity in representation between white and non-white geoscientists is not happenstance. Recent articles (e.g., Dutt 2020) and calls to action (NoTimeForSilence.org) have explicitly connected the lack of diversity in STEM with institutional racism, a concept coined by Ture and Hamilton (1967), also referred to as "systemic racism." Though many variations in the definition of the terms "institutional" or "systemic" racism exist, the essence is a difference in the provided level of products, goods, services, results, or opportunities of society based upon discrimination associated with race, skin color, culture, ethnic origin, or some other characteristic of a particular group (Ture and Hamilton 1967; Jones 1996). Institutional racism is often embedded within normal practices and can intersect multiple systems (e.g., education, transportation, recreation, housing, employment).

This essay describes the urgency of building a diverse and inclusive workforce in coastal and estuarine science. Our vision couples the importance of workforce representation for the communities we serve with an effort to use inclusion and diversity initiatives as a mechanism for social justice and to address institutionalized racism, which is deeply rooted in the geosciences (Dutt 2020). Cuker (2020) has highlighted the important role of the individual in realizing change around racism. Professional societies, as institutional actors, can play a key role in dismantling racism and broadening participation in science (Morris and Washington 2017; Mourad et al. 2018). We contend that scientific societies can be natural agents of positive change in this regard and that they have an obligation to do so. We share a case study of work by the Coastal and Estuarine Research Federation (CERF) to articulate a way forward to achieve greater belonging, equity, and inclusion in the geosciences.

\section{A Mismatch Between Coastal Communities and Coastal Scientists}

The demographic trends in ocean science graduation rates in the USA have particularly disturbing implications for estuaries and coasts in terms of inclusion and diversity of coastal populations and cultures. Many USA estuarine areas are highly urbanized, are diverse in ethnic and racial identities, and contain high concentrations of socially vulnerable populations. We performed an independent sample $T$-test comparing the racial and ethnic composition of coastal, non-coastal, and shoreline areas which provided empirical evidence of these differences. In contrast to the trends in racial and ethnic characteristics of ocean science graduates identified by Bernard and Cooperdock (2018), the populations of coastal (defined as counties within the boundaries of coastal watersheds) and shoreline areas (defined as counties directly next to the ocean) are more diverse than non-coastal areas (Fig.1). Nearly across the board, average populations of Blacks, Hispanics, Asians, and Native Americans are higher (sometimes substantially) in USA coastal and shoreline areas than non-coastal and non-shoreline areas. Although Black and Hispanic populations predominate in coastal areas, it is important to note that Asian populations (on average) are also more than two- to threefold higher in coastal and shoreline counties, respectively.

Although race, ethnicity, and gender were the variables used in comparing graduation rates by Bernard and Cooperdock (2018), it is well known that a myriad of other characteristics add to the barriers preventing underrepresented groups from pursuing educational opportunities in the geosciences. To more fully understand the disparities between a mostly white, non-Hispanic population of coastal 

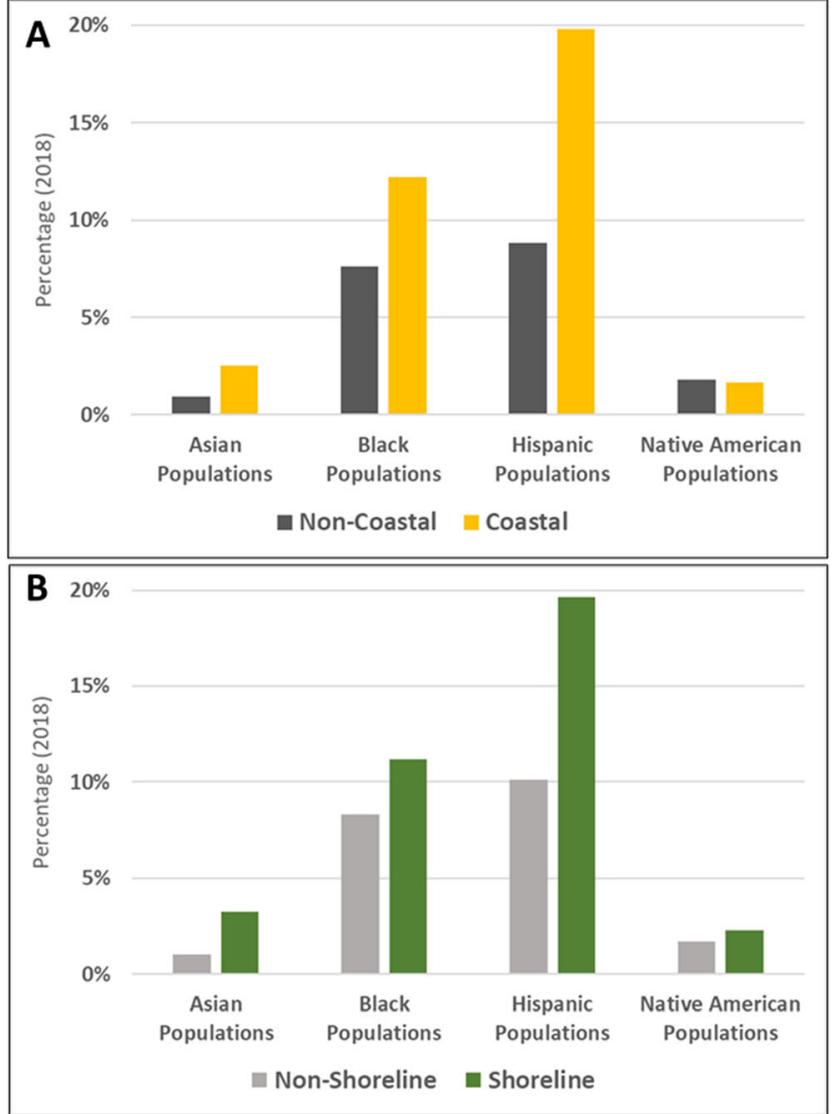

Fig. 1 US county averages of racial and ethnic composition in a coastal vs. non-coastal areas and b shoreline vs. non-shoreline areas. Data source: US Census Bureau (2019) and NOAA (2021). Coastal counties fall within coastal watersheds; shoreline counties are located directly adjacent to coastal shorelines. Because coastal watersheds can be quite large, shoreline counties may be more susceptible to coastal hazards

geoscientists and the diversity across the coastal zone, we used the Social Vulnerability Index (SoVI $囚)$ and its constituent indicators for USA and Puerto Rico ${ }^{1}$. SoVI measures 29 specific socio-economic and demographic characteristics influencing individual and community capacity to prepare for, respond to, and rebound from environmental shocks or stressors including coastal hazards (Emrich and Cutter 2011). At the county level, SoVI variables are standardized based on population. Figure 2 depicts county-level social vulnerability using five classes, where counties shaded red and pink have higher vulnerability and counties shaded blue and light blue have lower social vulnerability. Patterns of increased social vulnerability in coastal areas (highlighted in light green) can be seen along every coastline, with particularly high social vulnerability in Alaska, Puerto Rico, Southern Texas, Florida's west coast, the mid-Atlantic region, the Northwest, and in some areas of the Great Lakes. Non-coastal areas have a larger proportion of low vulnerability counties than high

\footnotetext{
${ }^{1}$ Lack of detailed US Census data for other US Territories prevents the inclusion of Guam and the USVI in the analysis.
}

vulnerability counties, whereas coastal and shoreline areas have markedly more medium-high and high vulnerability counties (Fig. 3). Interestingly, a comparative assessment of population percentages across coastal, non-coastal, and shoreline areas finds that coastal areas have more people living in vulnerable counties (Fig. 3). The mismatch in sociodemographics between those living in coastal areas and those managing and studying coastal problems portends a growing challenge to inclusive diversity that, if left unaddressed, could lead to continued and possibly increased inequity for the most vulnerable in society. Indices of social vulnerability are similarly being applied around the world in the context of coastal hazards (e.g., Chen et al. 2013; Rabby et al. 2019; Kim and Gim 2020). While a parallel analysis contrasting coastal and non-coastal populations and social vulnerabilities has not yet been completed at the global scale, the demographics of the world's population suggests that similar patterns may emerge and such an analysis could certainly illuminate the intersection of community and research needs.

There are multiple approaches to incorporating human dimensions of environmental issues into natural resource management (reviewed by Bennett et al. 2017). Stakeholder engagement is widely recognized as essential to building community support for natural resource management and conservation projects, including estuaries (e.g., Gregory and Wellman 2001; Hutchison et al. 2015; Paolisso et al. 2015; Harris et al. 2021), while increasing the quality of decision-making (Talley et al. 2016; Sterling et al. 2017). It stands to reason that including broad representation among stakeholders who are relevant to the decision-making context will improve the salience of solutions (e.g., Stringer et al. 2006; Yamineva 2017). Yet case studies of stakeholder engagement in natural resource management often fail to identify how or why stakeholders were selected (Talley et al. 2016) or define them solely by the institutional diversity they represent (e.g., Creed et al. 2018; DeLorme et al. 2016). The social justice rationale for stakeholder engagement in coastal decision-making is rarely argued for or included in initial project planning or design (but see Cooper and McKenna 2008; Nurhidayah and Mcllgorm 2019). This omission leaves the representativeness of the stakeholders, particularly within Black, Hispanic, Asian, and Indigenous communities, in question. That is, those higher proportions of vulnerable and underrepresented groups who live and work in the coastal areas are omitted from the decision-making process that will likely disproportionately impact their quality of life.

There is an urgent need to increase racial and ethnic diversity in coastal and estuarine science to increase creativity and innovative problem-solving within the complex ecological, economic, and social processes that shape our coastal environments (see Medin and Lee 2012; Hong and Page 2004; Page 2017). There are a small number of well-articulated visions and programs that can provide a template for moving towards greater equity in these areas. For example, the Chesapeake Bay Program has recently 


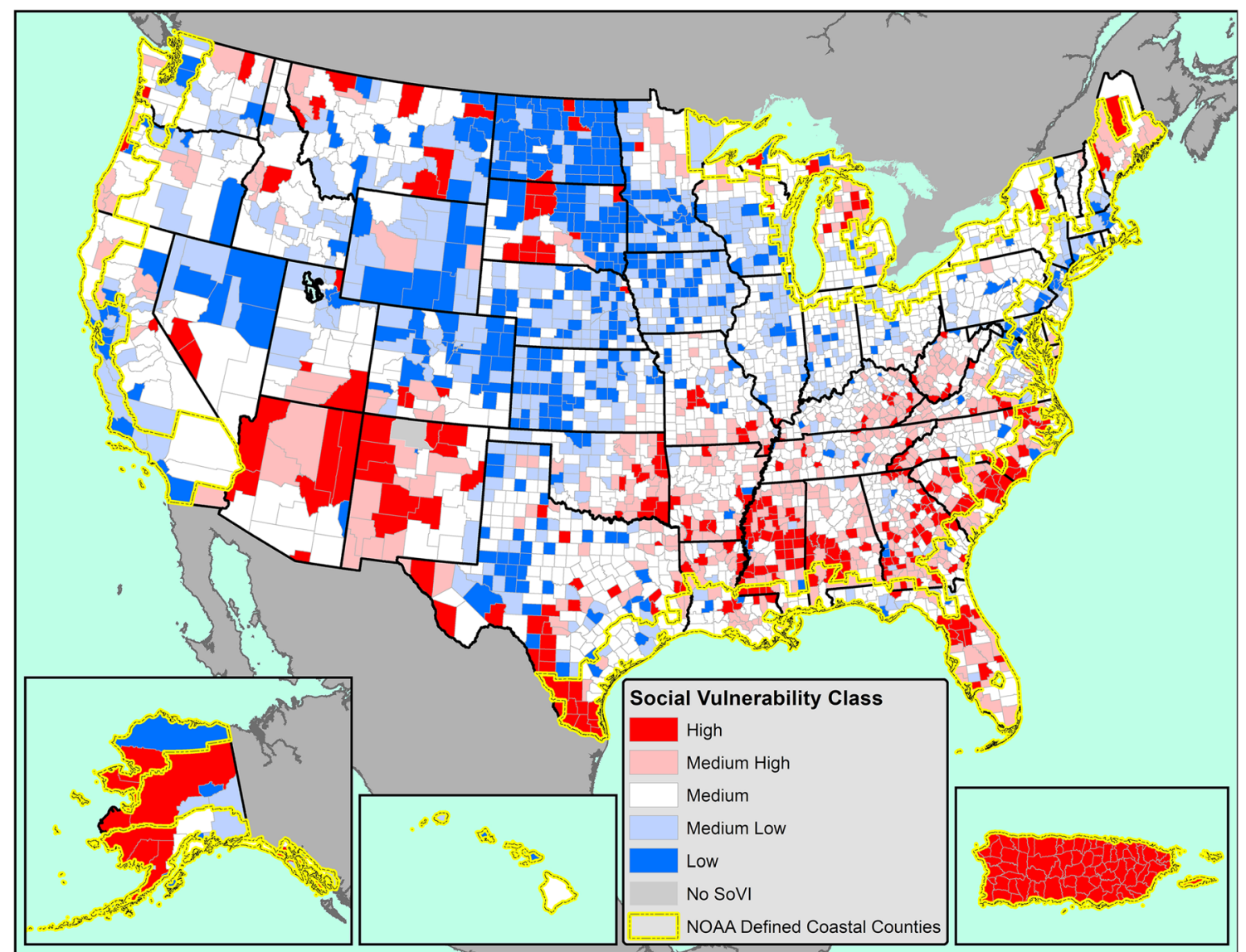

Fig. 2 Social Vulnerability Index (SoVI) classes by county for the USA and Puerto Rico. Data gaps in Guam and the US Virgin Islands prohibit calculation of the SoVI metric. It is notable that these two US territories have large populations of Native Hawaiian and Pacific Islanders, Asians, and Black or African Americans. Data source: US Census Bureau, 2018 American Community Survey 5-Year Estimates, using data at https:// data.census.gov/cedsci (13 Nov 2020)

white majority community have a responsibility to also reckon with more challenging barriers that have contributed to a lack of progress in recruitment and retention in the geosciences over the past 40 years (Bernard and Cooperdock 2018; Dutt 2020). Social scientists are documenting how exclusive climates on campus and in the field, lack of access to mental health resources, and implicit bias affect students from underrepresented communities as they enter the geosciences, even as parental and mentoring support can encourage persistence and facilitate resilience (cf. Allen-Ramdial and Campbell 2014; Anadu et al. 2020). In addition to making coastal science more relevant to Black, Hispanic and Latino, and Indigenous communities as a means to increase recruitment, we must also complement these efforts with a focus on inclusion. This element of social justice, accepting that ethnic and racial biases have led to patterns of exclusion, is just as critical to the path forward as valuing diversity for innovation and creativity in the sciences. This acceptance is ultimately necessary to create a working climate in the coastal sciences that fosters a sense of belonging for all members as a hallmark of an inclusive professional culture. 

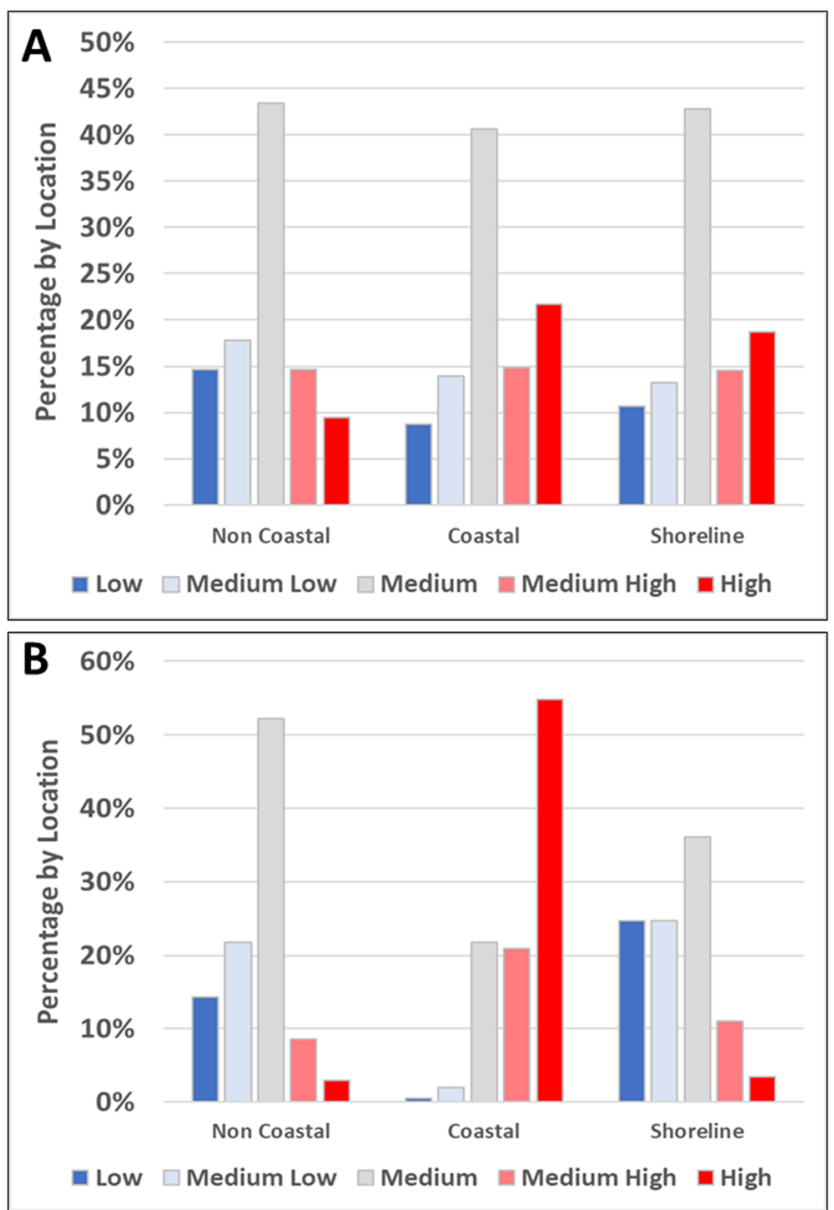

Fig. 3 Social vulnerability class within the USA by non-coastal, coastal, and shoreline areas and a percent of population and $\mathbf{b}$ percent of counties

\section{The Role of Scientific Societies}

Professional societies, through their role in helping to codify cultural expectations (McKnight 1998), have unique opportunities and obligations to enhance diversity and inclusion in STEM (Morris and Washington 2017; Mourad et al. 2018). Dutt (2020) identifies the important role of leadership in scientific societies, where a history of white representation and affinity bias propagates into executive and editorial boards as well as society awardees, reinforcing the dominant white culture and perpetuating institutionalized racism. It is increasingly clear that in addition to breaking down well-documented barriers to entering higher education, including socioeconomic factors and expectations of family and community (e.g. National Research Council 2011; Garza 2015), promoting success of underrepresented students along STEM career development pathways depends critically on dismantling institutional bias and social injustice that lead to attrition (Tienda 2013; Allen-Ramdial and Campbell 2014; Puritty et al. 2017). The key is cultivating a climate of inclusion or practices that promote "meaningful social and academic interactions among persons and groups who differ in their experiences, their views, and their traits" (Tienda 2013). Increased emphasis on creating environments, such as scientific societies, in which all people feel welcomed and respected, individual and intersectional identities are valued, and differences are embraced, is fundamental to retaining scientists' racial, ethnic, and cultural identities. In Fig. 4, we outline key characteristics of these relationships between diversity, inclusion, and science. These are expanded below in regard to scientific societies, highlighting several geoscience organizations while using CERF's activities to articulate specific actions.

Inherent to engaging diverse perspectives in solving coastal and estuarine problems is building a more diverse and inclusive workforce. Scientific societies can adopt complementary strategies to enhance three types of diversity described by the Kardia Group (2017): representational, structural, and interactional diversity. Models for increasing representational diversity, or the proportional representation of members from all social identities in institutions and organizations, exist in STEM fields including ocean sciences. CERF's Broadening Participation Comprehensive Plan (Coastal and Estuarine Research Federation 2019) incorporates some methods widely used in academia and other scientific societies, including outreach to high school students, expanded financial support for participation in CERF activities by students underrepresented in STEM, and underrepresented student mentorship during and outside of CERF conferences. It is also critical to look for representation beyond R1 Institutions (i.e., the Carnegie Classification of doctoral universities with very high research activity), in particular seeking representation from MSIs such as Historically Black Colleges and Universities, Hispanic Serving Institutions, and Tribal Colleges and Universities. Indeed, a number of co-authors on this essay draw on their professional and personal experiences from MSIs where diversification of perspectives in coastal systems and broadening participation in research and training are key components for increasing access to STEM fields. More novel approaches include seeking connections to the communities in which conferences are located to bring diverse local perspectives into conversations on coastal and estuarine science and sustainability. Commitments to increase the structural diversity of CERF, or the incorporation of diversity into leadership, policies, and practices, provide a mechanism for change that can ultimately be translated to the profession. Such initiatives include promoting diversity throughout all levels of the organization, including plenary conference roles and society leadership, and ensuring that conference topics relevant to broadening participation are not siloed in special sessions but rather are distributed throughout the scientific program to improve exposure to all members and participants (see Burnett et al. 2020). The Association for the Sciences of Limnology and Oceanography has had success in this realm, electing members to the Board of Directors who came through their wellknown Multicultural Program. This program exemplifies how 


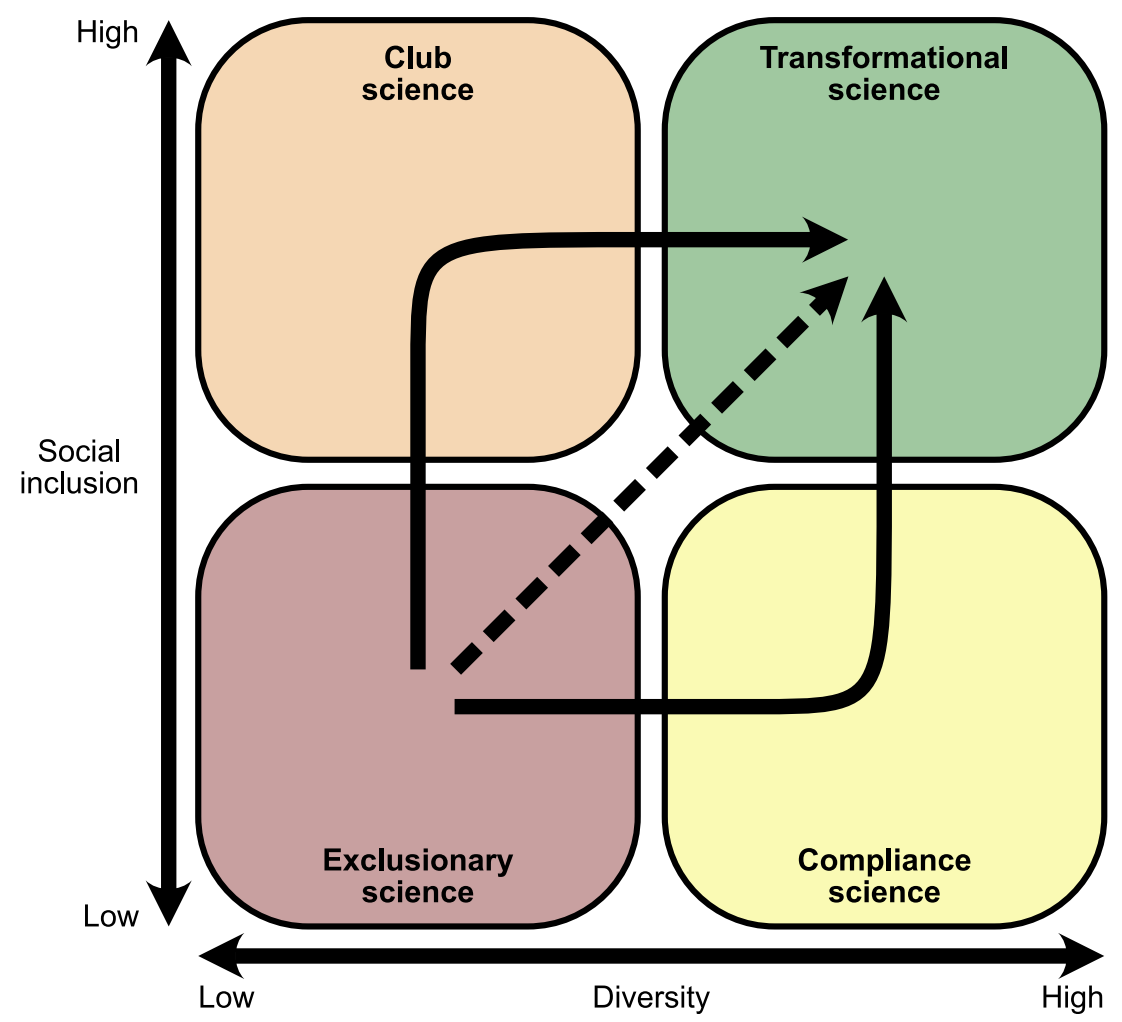

Fig. 4 Scientific teams, organizations, and professional societies that have low diversity and low social inclusion, practice exclusionary science (red quadrant), while those with higher social inclusion but still low diversity practice club science (orange quadrant, high social cohesion but homogeneous in nature). Scientific teams, organizations, and professional societies that have higher diversity but low social inclusion practice compliance science (yellow quadrant), which may have elements of interactional or structural diversity. Scientific teams, organizations, and professional societies that exhibit high diversity and high social inclusion exhibit elements of greater interactional, structural, and representational diversity and practice transformational science, resulting in greater innovation and impact (green quadrant). Scientific teams, organizations, and professional societies may be at different places within the four quadrants or even within a specific quadrant. Scientific teams, organizations, and professional societies can move directly from exclusionary to transformational sciences (dashed arrow) but are more likely to move through transitional quadrants (solid arrows). Interactional diversity (ID) is what moves scientific teams, organization, and professional societies into the transformational science space and sustains them once there, but only through an intentional and iterative process of commitment to both diversity and social inclusion.

mentors to become sponsors who actively promote their protégés. At CERF, we see a sustained role for in-person and remote conference workshops and webinars to ensure that the resources and training developed for these purposes continue to improve the literacy of our white majority membership. Literacy development can come from multiple sources to avoid inadvertently reallocating resources (time, energy, focus, etc.) of underrepresented members. Additionally, CERF anticipates offering networking and training as well as iterative identification and response to additional concerns from members who do not identify with majority identities in order to support a sense of belonging and inclusion. Achieving progress towards enhancing diversity, equity, inclusion, and justice in the scientific enterprise, including scientific societies, requires commitments to all three types of diversity at all levels, from the institutional mission to everyday affairs (National Research Council 2011).

One key step in creating this inclusive environment is effective mentoring, which here we identify as having a critical result in workplace diversity and allyship; and training 
impact on representational diversity. Effective mentoring is a valued tool for professional development in general and is one of the most important contributors to success of underrepresented students in STEM (National Research Council 2011; Kendricks et al. 2013; Allen-Ramdial and Campbell 2014), especially when tools and training are provided for mentors Within the ocean and aquatic sciences, several professional societies stand out for their long-standing, sustained conference mentoring programs that have served as models for other societies' efforts to build diversity. For example, the American Geophysical Union (AGU), the Association for the Sciences of Limnology and Oceanography (ASLO), and the Society of Wetland Scientists (SWS) all have well-established mentoring programs that have benefited scores of students. Each society's program has a unique flavor, but common to all are mentors who help students navigate scientific sessions, career mixers, and other networking events. These initiatives have succeeded in attracting and retaining scientists with diverse identities to careers in ocean and aquatic sciences and receive high marks from past mentees as being crucial to their professional development and persistence in STEM (Cuker et al. 2016; Johnson et al. 2016).

At its 2017 conference, CERF embarked on deepening conversations related to building and embracing diversity in the society and the profession. Discussions were launched in pre-conference workshops and were propagated through a conference mentoring program (Rising TIDES [Toward an Inclusive, Diverse, and Enriched Society] Conference Program), a parallel conference-wide mentoring program, an Inclusion Luncheon, and various scientific sessions. All of these activities were affirmed from the podium during highprofile plenary events. The aim of this work was to increase awareness of inclusive diversity, identify how multiple social identities shape interactions, and point out the hidden biases that influence engagement. These represented efforts to shape interactional diversity. The increased awareness fostered through these initiatives led to a comprehensive plan for creating a culture and climate of inclusion within CERF, within members' home institutions, and by extension, within coastal and estuarine science at large. Through this plan, CERF accepted the responsibility to begin to break down systemic inequalities in the scientific society and move coastal disciplines forward in ways that are unique to the Federation and the context of coastal science in a changing world. Coincident with this work, the CERF Code of Ethics, Event Code of Conduct, and bylaws were updated to identify specific behavioral responsibilities surrounding any form of harassment, intimidation, and bullying. These mechanisms function together to promote free expression and scientific exchange for all in safe, inclusive environments. In 2018, CERF was among the first scientific societies in the geosciences with the capacity to end membership for violating a code of conduct. The conversations and work around these efforts fundamentally integrated broadening participation goals into CERF's fourth strategic plan, covering the period from 2017 to 2022 (Coastal and Estuarine Research Federation 2018), in an effort to improve both interactional and structural diversities, and this work has continued and expanded through activities at its 2019 and 2021 conferences. For example, the 2021 conference will include an expanded Rising TIDES Conference Program and a new society-level award to honor the significant contributions of an individual who has worked for greater justice, equity, diversity, and inclusion in estuarine and coastal science, management, education, and/or stewardship, thus highlighting work that is too often undervalued or perceived as tangential, rather than essential to, the discipline.

\section{Leveraging Diversity and Inclusion Efforts to Achieve Transformational Science Through Collective Impact}

Beyond the bounds of an organization's membership rolls, many scientific societies articulate a public service mission that seeks to connect progress in the scientific endeavor to real-world challenges. In order to determine the needs of diverse stakeholders in coastal communities, there is a need for intentional engagement, especially when these organizations lag behind in representational diversity. Boundary organizations work across societal sectors to bridge the gaps among various stakeholders and provide the link between scientific understanding and public policy and management (Parker and Crona 2012). Professional societies can and should serve as boundary organizations in service to greater justice, equity, diversity, and inclusion. Conversations and informationgathering should be undertaken with various groups or individuals within the society itself, and within coastal communities. A key factor in community engagement success is conducting outreach through or in partnership with an organization that has established and trusted relationships and cultural knowledge within a geographic area (Mann et al. 2017). This approach enables the scientific organization to connect to appropriate partners and to establish trust among stakeholders. If used appropriately, through formation of intentional and meaningful partnerships with residents of coastal watersheds, societies could facilitate engagement of diverse perspectives on coastal issues and recruitment of and outreach to underrepresented coastal communities. For example, large organizations like the AGU have gone as far as to invest in entire centers committed to this through their Thriving Earth Exchange that cultivates boundary spanners who can traverse mainstream research and stakeholder communities (Safford et al. 2017). The URGE movement (Unlearning Racism in Geoscience initiative: https://urgeoscience.org/) has led to widespread efforts at geoscience institutions to begin the work of advancing anti-racist policies and practices. CERF 
has initiatives related to the National Science Foundation's INCLUDES (Inclusion across the Nation of Communities of Learners of Underrepresented Discoverers in Engineering and Science) to create pathways for islanders from US territories in the marine sciences that emphasize cultural competence as an avenue for improved sense of belonging and identity in the geosciences. With a focus on coastal waters of the USA, the National Oceanographic and Atmospheric Administration (NOAA) supports four Cooperative Science Centers that have missions centered around funded training opportunities with NOAA scientists for underrepresented identities in the ocean sciences. The centers not only provide training opportunities for students but also help support the development of a diverse future workforce for NOAA who can support the agency's emerging research needs. Additional efforts to cultivate an inclusive coastal community are particularly evident in the National Sea Grant network, especially as a consequence of the Sea Grant Diversity Equity and Inclusion Community of Practice (NOAA Sea Grant 2018), and regional partnerships such as the Woods Hole Scientific Community Diversity Initiative (Woods Hole Diversity Advisory Committee 2021).

Professional societies can help scientists navigate and intentionally engage all constituents of coastal communities in conversations around issues of management and mitigation of impacts to coastal ecosystems. There is a history of stakeholder engagement in science-based coastal management, but it is critical to engage all sectors that have vested interest in coastal issues and that bring unique perspectives and solutions to persistent environmental impacts. As noted in studies that gather data from a diverse range of participants (e.g., Gupta et al. 2018), community engagement efforts should aim to avoid creating in-group dialogues that might exclude entire sectors of the community or favor the most outspoken or already known sectors, creating unintended bias. This bias, historically fueled by institutional racism and the unwillingness to merge environmental issues with those of social justice and activism, marginalized and excluded Black, Hispanic, Asian, and Indigenous peoples from the mainstream environmental movement (Chavis 1987). As a result, the environmental sector and mainstream environmental organizations traditionally lack diversity (Taylor 1997), which has become a top priority and focus of organizational strategies and initiatives to enhance diversity, equity, and inclusion.

\section{Looking Ahead}

Professional societies play a key role in transforming coastal science disciplines. However, transformation will only occur when individuals, teams, organizations, and professional societies not only commit to changes that result in greater representational and structural diversity but also create op- portunities for greater interactional diversity and social inclusion (Fig. 4). For societies and disciplines who are predominantly white, this involves dismantling the practice of exclusionary, club, and compliance science (Fig. 4), and importantly, committing to the work required for this change. Such work is not only long overdue and essential to estuarine and coastal science and management, but it is also a moral imperative.

Definitions Box 1.

Representational diversity (RD): The proportional representation of individuals from all social identities in institutions and organizations

Structural diversity (SD): The incorporation of equitable representation into leadership, policies, and practices, providing a mechanism for change that can ultimately be translated to the profession

Interactional diversity (ID): The opportunity for people with varied backgrounds and life experiences to interact in meaningful ways. The empowerment of groups to effectively capitalize on the benefits of diversity

Social inclusion: Embeddedness in the social context and fabric of a group based on relational bonds (after Fredette et al. 2016). Such relational bonds may form within affinity groups or among individuals who differ in their ethno-cultural backgrounds and experiences

Exclusionary science: Exhibits non-existent to low levels of inclusion, $\mathrm{RD}, \mathrm{SD}$, and ID. Maintains majority group dominance and privilege

Club science: Exhibits high, within-group inclusion but is restricted in the set of groups represented, resulting in low to medium levels of RD and SD. Club science can include affinity groups for scientists historically outside of mainstream science who support and champion one another (e.g., \#BlackInMarineScience). However, more commonly club science has been used to maintain power structures, where participation from non-majority groups is limited via active gate-keeping in order to maintain comfort level and terms established by the majority group

Compliance science: Exhibits medium to high levels of RD and SD, but low levels of inclusion. Compliance "checks the box" on diversity initiatives and/or EEO requirements but demands cultural assimilation and does not promote inclusion. Permits access to previously excluded non-majority groups through token hires and promotions without changing the organizational culture

Transformational science (TS): Exhibits medium to high levels of RD, $\mathrm{SD}$, and ID and high levels of social cohesion, resulting in greater innovation and impact while achieving social justice outcomes. Authentic inclusion of non-majority groups as full participants at all levels and in all decisions, enhancing capabilities and competencies

Definitions derived and adapted from the work of: Fredette and Bradshaw (2007), Fredette et al. (2016), Jackson (2014), Kardia Group (2017), and Page (2017).

Acknowledgments This synthesis is based upon the work supported by the National Science Foundation under Grant Numbers 1930869, 1928845, 2036515, 1930991, and 1645467. This essay was co-authored by CERF's Broadening Participation Council. This essay was improved by the comments of Eleanour Snow and two anonymous peer reviewers. The authors thank Roel Fleuren from Science Transmitter for assisting in the creation of the conceptual framework figure for this manuscript. Work on this manuscript during the pandemic was possible for Harris with the support of childcare from Jamie Testa, Chelsea Ihnacik, Lisa Dorsey, and Rebecca Wingate. Feedback regarding the essay is welcomed at bpc@cerf.science 
Open Access This article is licensed under a Creative Commons Attribution 4.0 International License, which permits use, sharing, adaptation, distribution and reproduction in any medium or format, as long as you give appropriate credit to the original author(s) and the source, provide a link to the Creative Commons licence, and indicate if changes were made. The images or other third party material in this article are included in the article's Creative Commons licence, unless indicated otherwise in a credit line to the material. If material is not included in the article's Creative Commons licence and your intended use is not permitted by statutory regulation or exceeds the permitted use, you will need to obtain permission directly from the copyright holder. To view a copy of this licence, visit http://creativecommons.org/licenses/by/4.0/.

\section{References}

Allen-Ramdial, S.A., and A.G. Campbell. 2014. Reimagining the pipeline: advancing STEM diversity, persistence, and success. Bioscience 64 (7): 612-618.

Anadu, J., H. Ali, and C. Jackson. 2020. Ten steps to protect BIPOC scholars in the field. Eos 101. https://doi.org/10.1029/ 2020EO150525.

Bennett, N.J., R. Roth, S.C. Klain, K. Chan, P. Christie, D.A. Clark, G. Cullman, D. Curran, T.J. Durbin, G. Epstein, A. Greenberg, M.P. Nelson, J. Sandlos, R. Stedman, T.I. Teel, R. Thomas, D. Berissimo, and C. Wyborn. 2017. Conservation social science: understanding and integrating human dimensions to improve conservation. Biol Conserv 205: 93-108.

Bernard, R.E., and E.H.G. Cooperdock. 2018. No progress on diversity in 40 years. Nat Geosci 11 (5): 292-295. https://doi.org/10.1038/ s41561-018-0116-6.

Blicharska, M., R.J. Smithers, M. Kuchler, G.K. Agrawl, J.M. Gutierrez, A. Hassanali, S. Huq, S.H. Koller, S. Marjit, H.M. Mshinda, H.H. Masjuki, N.W. Solomons, J.V. Staden, and G. Mikusinki. 2017. Steps to overcome the North-South divide in research relevant to climate change policy and practice. Nat Clim Chang 7 (1): 21-27.

Burnett, N.P., E.E. King, M.K. Salcedo, R.L. Tanner, and K. Wilsterman. 2020. Conference scheduling undermines diversity efforts. Nat Ecol Evol: 1-2.

U.S. Census Bureau. 2019. 2014-2018 ACS 5-year estimates. https:// www.census.gov/programs-surveys/acs/technical-documentation/ table-and-geography-changes/2018/5-year.html. .

U.S. Census Bureau. 2020. Explore Census Data. https://data.census.gov/ cedsci/.

Chavis, B. 1987. Toxic Wastes and Race. United Church of Christ. New York: Commission for Racial Justice.

Chen, W., S.L. Cutter, C.T. Emrich, and P. Shi. 2013. Measuring social vulnerability to natural hazards in the Yangtze River Delta region, China. Int J Disaster Risk Sci 4 (4): 169-181.

Coastal and Estuarine Research Federation (CERF). 2018. Visions IV: a strategic plan for the coastal and estuarine research federation (20172022). https://www.erf.org/assets/docs/2017/CERF_Visions_IV_ Brochure_Web.pdf.

Coastal and Estuarine Research Federation (CERF). 2019. CERF Broadening Participation Comprehensive Plan. https://cerf. memberclicks.net/assets/site/CERF_Broadening_Participation Comprehensive_Plan.pdf.

Cooper, J.A.G., and J. McKenna. 2008. Social justice in coastal erosion management: the temporal and spatial dimensions. Geoforum 39 (1): 294-306

Creed, R., B. Baily, J. Potts, M. Bray, and R. Austin. 2018. Moving towards sustainable coasts: a critical evaluation of a stakeholder engagement group in successfully delivering the mechanism of adaptive management. Mar Policy 90: 184-193.
Cuker, B. 2020. George Floyd and Aquatic Science. Limnol Oceanogr Bulletin 29 (3): 73-74. https://doi.org/10.1002/lob.10392.

Cuker, B., C. Haxton, and C. Martinez. 2016. How a scientific society built multicultural diversity: a 25-year-long journey. Biosciences 66 (3): 238-244.

Delaine, D.A., R. Tull, R. Sigamoney, and D.N. Williams. 2016. Global diversity and inclusion in engineering education: developing platforms toward global alignment. Int J Eng Pedagogy 6 (1): 56-71.

DeLorme, D.E., D. Kidwell, S.C. Hagen, and S.H. Stephens. 2016. Developing and managing transdisciplinary and transformative research on coastal dynamics of sea level rise: experiences and lessons learned. Earth's Future 4 (5): 194-209.

Dutt, K. 2020. Race and racism in the geosciences. Nat Geosci 13 (1): 2-3.

Emrich, C., and S.L. Cutter. 2011. Social vulnerability to climatesensitive hazards in the southern United States. Weather Climate Society 3 (3): 193-208.

Fredette, C. and P. Bradshaw. 2007. Moving to transformational inclusivity and board diversity. Administrative Sciences Association of Canada 2007 conference, Ottawa.

Fredette, C., P. Bradshaw, and H. Krause. 2016. From diversity to inclusion. Nonprofit and Voluntary Sector Quarterly 45 (1_suppl): 28S-51S.

Garza, C. 2015. Reaching out to underserved communities. Mar Technol Soc J 49 (4): 8-12.

Gregory, R., and K. Wellman. 2001. Bringing stakeholder values into environmental policy choices: a community-based estuary case study. Ecol Econ 39 (1): 37-52.

Gupta, R., J. Fraser, C. Shane-Simpson, S. Danoff-Burg, and N. Ardalan. 2018. Estimating scale, diversity, and professional training of environmental educators in the U.S. Environ Educ Res 25: 75-91.

Harris, L., C. Garza, M. Hatch, J. Parrish, J. Posselt, J. Alvarez, E. Davidson, G. Eckert, K. Grimes, J. Garcia, R. Haacker, M.C. Horner-Devine, A. Johnson, J. Lemus, A. Prakash, L. Thompson, P. Vitousek, M.P. Martin, K. Reyes. In Revision. Equitable exchange: a framework for diversity and inclusion in the geosciences. American Geophysical Union Advances.

Hong, L., and S.E. Page. 2004. Groups of diverse problem solvers can outperform groups of high-ability problem solvers. PNAS 101 (46): 16385-16389.

Hutchison, L., P. Montagna, D. Yoskowitz, D. Scholz, and J. Tunnell. 2015. Stakeholder perceptions of coastal habitat ecosystem services. Estuar Coasts 38 (Suppl 1): S67-S80.

Jackson, B.W. 2014. Theory and practice of multicultural organization development. In The NTL Handbook of Organization Development and CHange: Principles, Practice and Perspectives, ed. B.B. Jones and M. Brazzel, 491 p. Wiley.

Johnson, A., M.J. Huggans, D. Siegfried, and L. Braxton. 2016. Strategies for increasing diversity in the ocean science workforce through mentoring. Oceanography 29 (1): 46-54.

Jones, J. 1996. Prejudice and Racism. McGraw-Hill. 2nd Ed.

Kardia Group. 2017. Three approaches to diversity, equity, and inclusion. Kardia Group website. https://kardiagroup.com/three-approachesdiversity-equity-inclusion/.

Karlsson, S., T. Srebotnjak, and P. Gonzales. 2007. Understanding the North-South knowledge divide and its implications for policy: a quantitative analysis of the generation of scientific knowledge in the environmental sciences. Environ Sci Pol 10 (7-8): 668-684.

Kendricks, K.D., K.V. Nedunuri, and A.R. Arment. 2013. Minority student perceptions of the impact of mentoring to enhance academic performance in STEM disciplines. J STEM Educ 14: 38-46.

Kim, J., and T.H.T. Gim. 2020. Assessment of social vulnerability to floods on Java, Indonesia. Nat Hazards 102 (1): 101-114.

Mann, A. N., P. Grifman, and J. F. Hart. 2017. The stakes are rising: lessons on engaging coastal communities on climate adaptation in Southern California. Cities and the Environment a(CATE). http:// digitalcommons.lmu.edu/cate/vol10/iss $2 / 6$ 
McKnight, D.M. 1998. Scientific societies and whistleblowers: the relationship between the community and the individual. Sci Eng Ethics 4 (1): 97-113.

Medin, D. L. and C. D. Lee. 2012. Diversity makes better science. APS Observer. Column in APS's Observer Series. http://www. psychologicalscience.org/index.php/publications/observer/2012/ may-june-12/diversity-makes-better-science.html Accessed 17 December 2020

Morris, V.R., and T.M. Washington. 2017. The role of professional societies in STEM diversity. JNat Tech Assoc 87: 22-31.

Mourad, T.M., A. Fox McNulty, D. Liwosz, K. Tice, F. Abbott, G.C. Williams, and J.A. Reynolds. 2018. The role of a professional society in broadening participation in science: a national model for increasing persistence. Bioscience 68 (9): 715-721.

National Research Council . 2011. Expanding underrepresented minority participation. Washington, DC: The National Academies Press.

National Science Foundation (NSF). 2019. Women, minorities, and persons with disabilities in science and engineering. http://www.nsf. gov/statistics/wmpd/.

National Oceanic and Atmospheric Administration (NOAA). 2021. Defining coastal counties. https://coast.noaa.gov/digitalcoast/ training/defining-coastal-counties.html.

Nurhidayah, L., and A. McIlgorm. 2019. Coastal adaptation laws and social justice of policies to address sea level rise: an Indonesian insight. Ocean Coast Manag 171: 11-18.

National Oceanic and Atmospheric Administration (NOAA) Sea Grant. 2018. Sea Grant Diversity, Equity and Inclusion. https://seagrant. noaa.gov/insideseagrant/Implementation/Network-Visioning/ DiversityInclusion.

Page, S.E. 2007. The difference: how the power of diversity creates better groups, firms, schools, and societies. Princeton: Princeton University Press.

Page, S.E. 2017. The diversity bonus: how great teams pay off in the knowledge economy. Princeton: Princeton University Press.

Paolisso, M., J. Trombley, R.R. Hood, and K.G. Sellner. 2015. Environmental models and public stakeholders in the Chesapeake Bay watershed. Estuar Coasts 38 (Suppl 1): S97-S113.

Parker, N., and B. Crona. 2012. On being all things to all people: boundary organizations and the Contemporary Research University. Soc Stud Sci 42 (2): 262-289. https://doi.org/10.2307/23210209.

Peterson, S.L., E.S. Erenrich, D.L. Levine, J. Vigoreaux, and K. Gile. 2018. Multi-institutional study of GRE scores as predictors of STEM PhD degree completion: GRE gets a low mark. PLoS One 13 (10): e0206570.
Puritty, C., L.R. Strickland, E. Alia, B. Blonder, E. Klein, M.T. Kohl, E. McGee, M. Quintana, R.E. Ridley, B. Tellman, and L.R. Gerber. 2017. Without inclusion, diversity initiatives may not be enough. Science 357 (6356): 1101-1102.

Rabby, Y.W., M.B. Hossain, and M.U. Hasan. 2019. Social vulnerability in the coastal region of Bangladesh: An investigation of social vulnerability index and scalar change effects. Int J Disaster Risk Reduc 41: 101329.

Safford, H.D., S.C. Sawyer, S.D. Kocher, J.K. Hiers, and M. Cross. 2017. Linking knowledge to action: the role of boundary spanners in translating ecology. Front Ecol Environ 15 (10): 560-568.

Solutions, Skeo. 2020. Restoration from the inside out: a diversity, equity, inclusion and justice strategy for the Chesapeake Bay Program. Chesapeake Bay Program https://www.chesapeakebay.net/ channel_files/41354/cbp_deij_strategy_final_v2.pdf.

Sterling, E.J., E. Betley, A. Sigouin, A. Gomez, A. Toomey, G. Cullman, C. Malone, A. Pekor, F. Arengo, M. Blair, C. Filardi, K. Landrigan, and A.L. Prozecanski. 2017. Assessing the evidence for stakeholder engagement in biodiversity conservation. Biol Conserv 209: 159171.

Stringer, L.C., A.J. Dougill, E. Frazer, K. Hubacek, C. Prell, and M.S. Reed. 2006. Unpacking "participation" in adaptive management of social-ecological systems: a critical review. Ecol Soc 11: 39.

Talley, J.L., J. Schneider, and E. Lindquist. 2016. A simplified approach to stakeholder engagement in natural resource management: the five-feature framework. Ecol Soc 21: 38.

Taylor, D.E. 1997. American environmentalism: the role of race, class and gender in shaping activism 1820-1995. Race Gender Class 5: $16-62$.

Tienda, M. 2013. Diversity $\neq$ inclusion: promoting integration in higher education. Educ Res 42 (9): 467-475.

Ture V. and C.V. Hamilton. 1967. Black power: politics of liberation (November 1992 ed.). New York: Vintage. ISBN 978-0679743132.

U.S. Department of Education. 2020. Completions component. National Center for Education Statistics, Integrated Postsecondary Education Data System (IPEDS) website. https://nces.ed.gov/ipeds/.

Woods Hole Diversity Advisory Committee. 2021. Woods Hole Diversity Advisory Committee website. https://www.woodsholediversity. org/.

Yamineva, Y. 2017. Lessons from the Intergovernmental Panel on Climate Change on inclusiveness across geographies and stakeholders. Environ Sci Policy 77: 244-251. 


\section{Affiliations}

\section{L.A. Harris ${ }^{1}$ (D) - T. Grayson ${ }^{2}$ - H.A. Neckles ${ }^{3}$ - C.T. Emrich ${ }^{4} \cdot$ K.A. Lewis ${ }^{5} \cdot$ K.W. Grimes ${ }^{6} \cdot$ S. Williamson ${ }^{7} \cdot$ C. Garza ${ }^{8}$ •

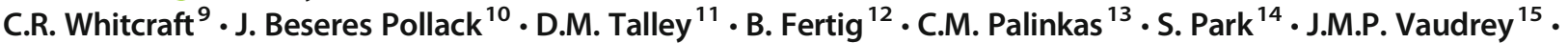 A.M. Fitzgerald ${ }^{16} \cdot$ J. Quispe ${ }^{17}$}

1 Chesapeake Biological Laboratory, University of Maryland Center for Environmental Science, Solomons, MD 20688, USA

2 US Environmental Protection Agency, 1200 Pennsylvania Ave, NW, Washington, DC 20460, USA

3 US Geological Survey, Eastern Ecological Science Center, 196 Whitten Road, Augusta, ME 04330, USA

4 School of Public Administration, National Center for Integrated Coastal Research, University of Central Florida, Orlando, FL 32816, USA

5 Department of Biology, National Center for Integrated Coastal Research, University of Central Florida, Orlando, FL 32816, USA

6 Center for Marine \& Environmental Studies, University of the Virgin Islands, 2 John Brewers Bay, St. Thomas, VI 00802, USA

7 National Association of Counties, 660 North Capitol Street NW, Washington, DC 20001, USA

8 School of Natural Sciences, California State University, Monterey Bay, Seaside, CA 93955, USA

9 Biological Sciences, California State University, Long Beach, 1250 Bellflower Blvd, Long Beach, CA 90840, USA
10 Harte Research Institute for Gulf of Mexico Studies, Texas A\&M University-Corpus Christi, 6300 Ocean Drive, Corpus Christi, TX 78412, USA

11 Environmental and Ocean Sciences, University of San Diego, 5998 Alcala Park, San Diego, CA 92110, USA

12 Ronin Institute for Independent Scholarship, Montclair, NJ 07043, USA

13 Horn Point Laboratory, University of Maryland Center for Environmental Science, Cambridge, MD 21613, USA

14 Coastal and Estuarine Research Federation, 2150 N 107th St, \#205, Seattle, WA 98133, USA

15 Department of Marine Sciences, University of Connecticut, 1080 Shennecossett Road, Groton, CT 06340, USA

16 Biology Department, New Jersey City University, 2039 Kennedy Blvd, Jersey City, NJ 07305, USA

17 Graduate Program in Ecology and Evolution, Rutgers University, 14 College Farm Rd, New Brunswick, NJ 08901, USA 